\title{
A FACTOR DETERMINING THE LOCATION OF PSEUDOFRACTURES IN OSTEOMALACIA
}

\author{
By M. LE MAY ${ }^{1}$ and J. W. BLUNT, JR. \\ (From the Departments of Radiology and Surgery, College of Physicians and Surgeons, \\ Columbia University, and the Radiological and Surgical Services, \\ The Presbyterian Hospital, New York)
}

(Received for publication October 11, 1948)

Narrow bands of diminished density, which resemble fracture lines and often appear symmetrically and last for months to years, have been described in the skeletons of individuals with a variety of diseases. The purpose of this paper is to offer a rational explanation for the bizarre locations of these pseudofractures as they occur in osteomalacia and to focus attention upon a possible mechanism for their occurrence.

The numerous descriptions of this phenomenon and the speculations as to its causes have been reviewed by Camp and McCullough (1). It has been described as a radiological syndrome by Milkman $(2,3)$. Histologically, such lesions in cases of rickets and osteomalacia were found by Looser $(4,5)$ to consist of infractions of the bones with subsequent laying down of non-calcified callus. Since they are not true fractures with complete separation of bone continuity, he called them umbauzonen, zones of alteration. $\mathrm{He}$ concluded that mechanical tension on softened bone, such as that due to muscle strain, perhaps caused small breaks in the cortex with gradual infractions through the rest of the bone, thus producing the long-lasting, symmetrical lines of diminished density resembling fracture lines. Callus about true fractures remains uncalcified for a long time in cases of osteomalacia, and Looser felt that it was not strange for these umbauzonen to persist for a considerable time after their first appearance.

Albright and coworkers (6) have reviewed the cases in which pseudofractures have been found. They state that the narrow decalcified bands which occur in otherwise normal-appearing bone, and which tend to be symmetrical and remain stationary for months to years, occur only in osteomalacia or rickets. They point out that the underlying bone disturbance in the variety of conditions where

\footnotetext{
1 Present address : Argonne National Laboratory, Chicago, Illinois.
}

these bands of diminished density have been noted, i.e., rickets, late rickets, celiac disease, chronic idiopathic steatorrhea, sprue, and severe acidosis, is really osteomalacia. The lesions are common in advanced cases of hunger osteopathy. Somewhat similar bands occur in Paget's disease, congenital syphilis, marble bones, osteogenesis imperfecta and hyperparathyroidism, but in these conditions the lesions are rarely symmetrical and occur through areas of definite bone abnormality as seen by X-ray. "March fractures" appear in otherwise normal bones but are rarely symmetrical and readily unite and become calcified. As for the mechanism of production of pseudofractures,

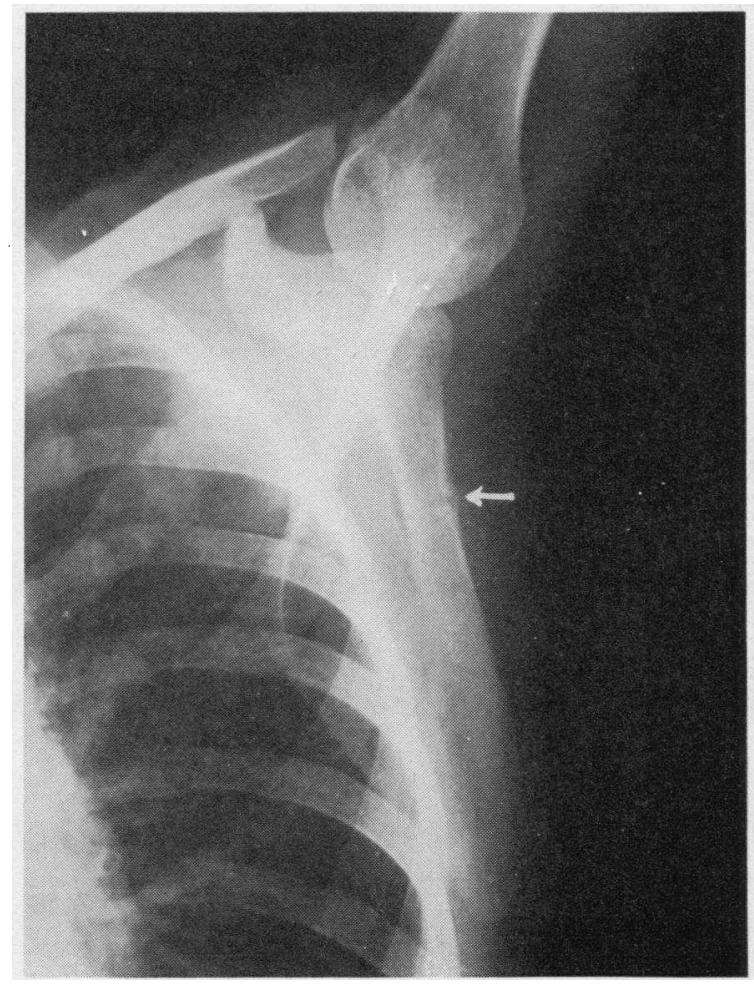

Fig. 1. Scapula Showing Pseudofracture 
Albright and coworkers refer to the work of Looser (4).

During the past year on the Radiological service of the Presbyterian Hospital, we have seen four patients with these narrow bands of lessened density. They all showed blood findings consistent with osteomalacia, i.e., normal calcium, low phosphorus and elevated alkaline phosphatase. One was a case of long-standing osteomalacia of unletermined origin; the other three showed the syndrome, described by Albright and coworkers (6), of renal acidosis without nitrogen retention. Pseudofractures occurred in similar locations in the bones of these four individuals. As in the published cases, the most common sites for these lesions were in the axillary border of the scapula (Figure 1), the ribs, the pubic rami, and the upper end of the femur. They also occur in the iliac bones (Figure 2), and near the base of the spine of the scapula (Figure 3 ).

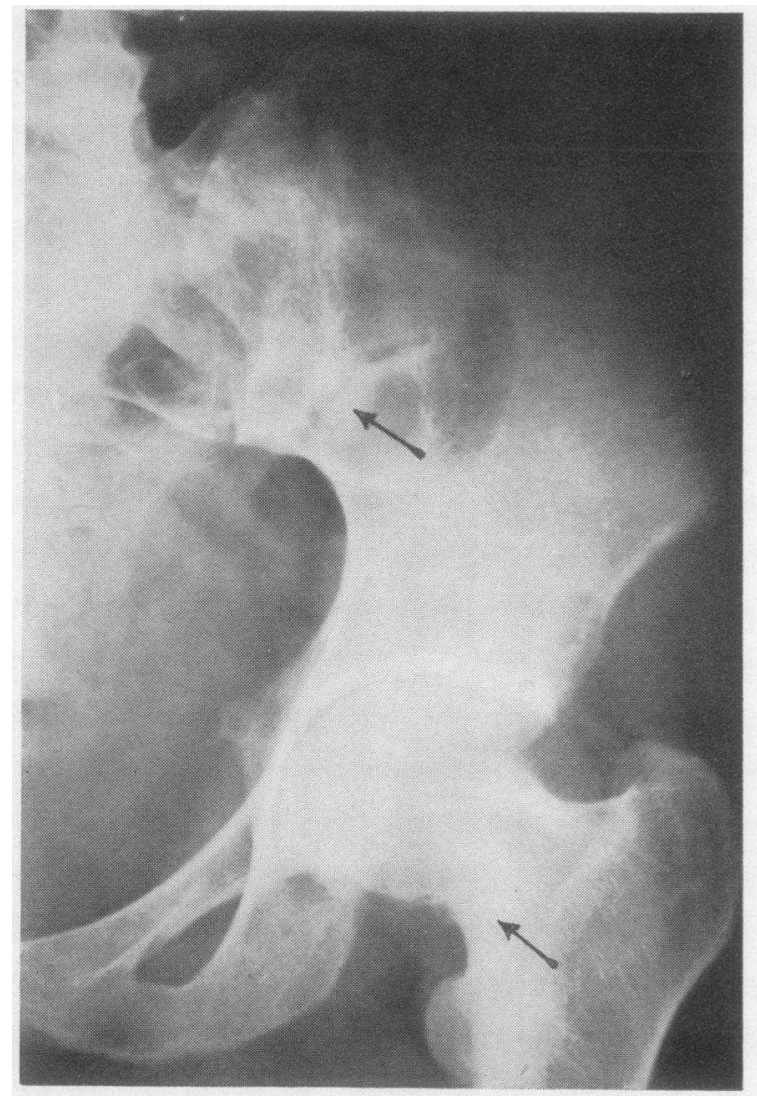

Fig. 2. Ilium and the Neck of a Femur Showing Pseudofractures

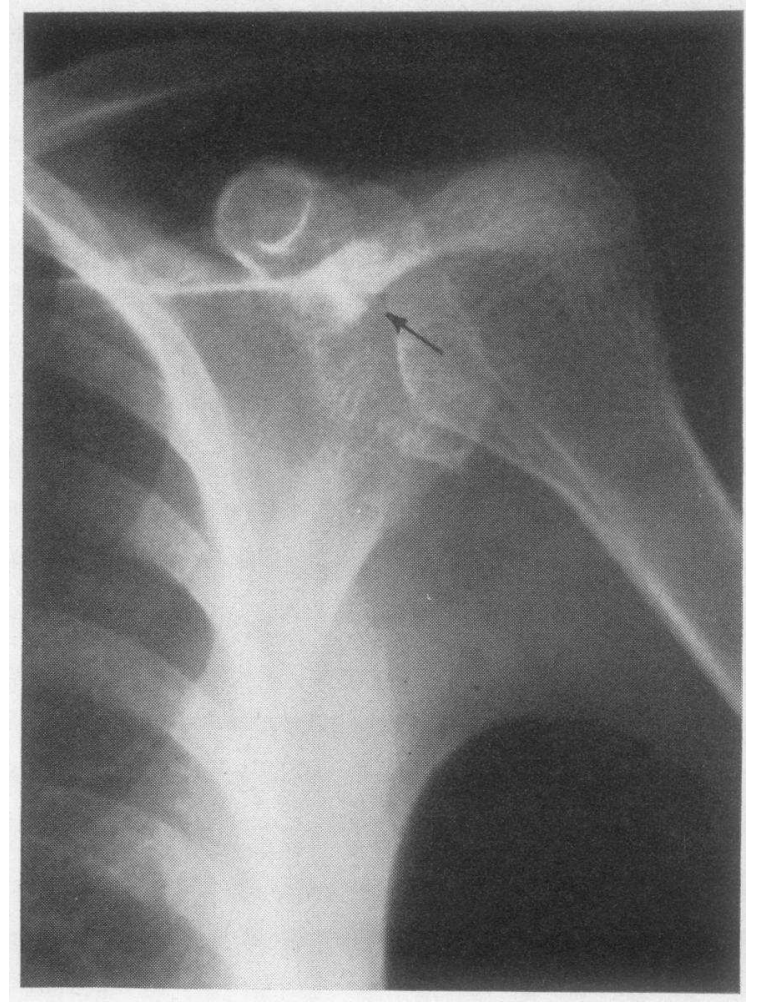

Fig. 3. Pseudofracture Occurring in the Spine of a Scapula. A Symmetrical. Lesion Is Present in the Opposite Scapula

The pseudofractures in the scapulae and the iliac bones, particularly, occur in areas where muscle strain seems unlikely. Since these lesions tend to develop regularly in the same places in different patients and tend to be symmetrical on the two sides of the body, an anatomical explanation for the lesions was sought.

\section{CLINICAL MATERIAL AND METHOD}

Complete skeletal radiographs were made of the four patients mentioned above. The reproductions of radiographs in cases reported in previous studies $(2,3,6-11)$ were reviewed and in 28 of these cases the illustrations were adequate to show accurate localization of the lesions. Dissection was made of the blood vessels supplying the trunks and extremities of three cadavers to ascertain the proximity of the main vessels to the bones.

\section{RESULTS}

The sites where pseudofractures have been found, and the arteries which commonly cross the bones at these sites, are shown in the two halves of Figure 4. The number of times lesions were found 


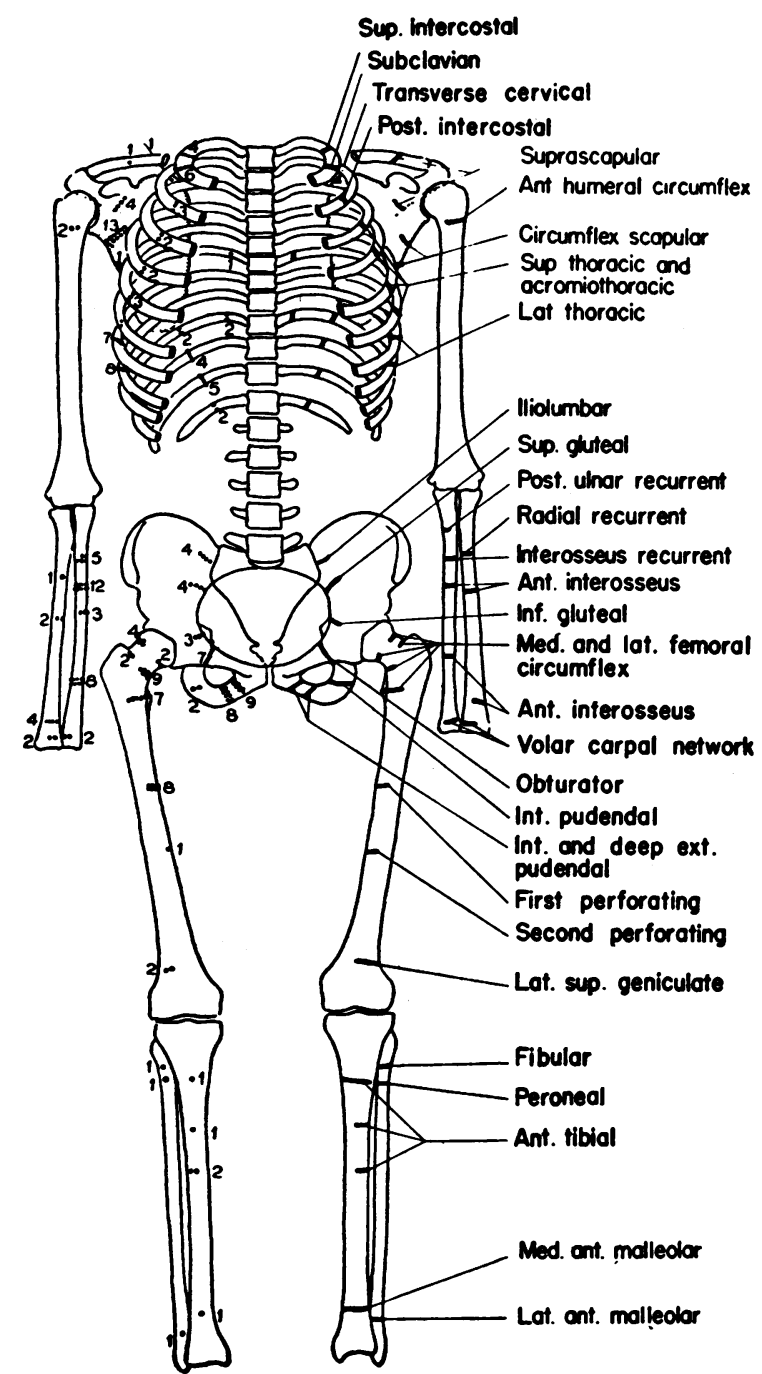

Fig. 4. Skeleton Showing the Usual Sites of Occurrence of Pseudofractures and the Arteries Which Course the Bones at these Sites

The figures signify the number of lesions found at these locations in four cases at the Presbyterian Hospital and the lesions pictured in previous studies $(2,3,6-11)$.

at these sites in our four cases and in which they were adequately pictured in the cases reported previously is indicated on the figure. The arteries shown are those coursing directly over the bones at the sites of the lesions as given in standard anatomy works $(12,13)$. All of these arteries were found by dissection to lie in contact with the bone. The blood vessels in the hands and feet vary considerably in different individuals in relation to the bones and therefore were not included in the figure.

\section{DISCUSSION}

Pseudofractures are not infrequent in the first rib where the bone is normally notched by the subclavian artery. In the axillary border of the scapula where the circumflex scapular artery grooves the bone, 13 pseudofractures were found. A detailed view of the blood vessels around the scapula is shown in Figure 5, and the close correspondence between the locations of these blood vessels and the scapular lesions shown in Figure 4 will be noted. A pseudofracture has also been described (3) in the outer end of the acromion at the site of the vessel shown in Figure 5.

Careful positioning of the patient is required at times to demonstrate some of the pseudofractures, particularly those in the ribs and scapulae. To be seen clearly, small incomplete fractures in normal bone due to trauma also require careful positioning of the patient. Both types of lesions are more distinct when they occur perpendicular to the long axis of the trabecular pattern of the bone. This could explain the failure of lesions to be common where the radial artery spirals the humerus. We have seen only one case (14), that of a severe rachitic infant, with bilateral symmetrical spiral lesions in the midportion of the humerus. Gross examination of normal scapulae shows that some of them are not grooved by the circumflex scapular artery. Variation in the course of this blood vessel may explain why pesudofractures are not

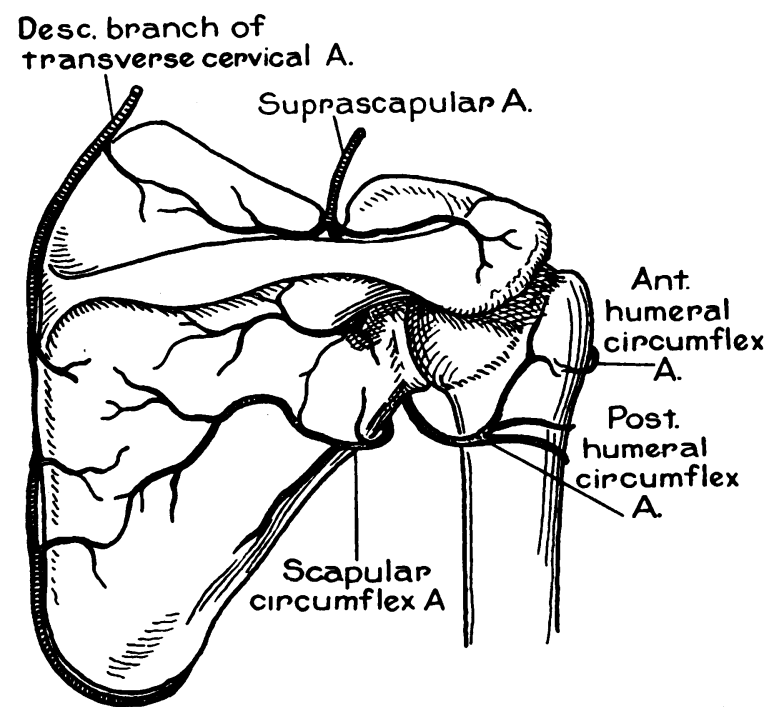

Fig. 5. Scapula Showing the Position of the Blood Vessels in Relation to the Bone 
always seen at this site. Similar variations of other blood vessels may produce the individual differences observed. The lesions in ribs nine, 10,11 , and 12 , and the posterior lesion in rib six could be at the site of branches of intercostal arteries. Vessels were found in these areas in one of three cadavers examined.

Mechanical stress, such as that due to muscular or postural strain, may produce true fractures at the site of pseudofractures, particularly in the upper end of the femurs in the far advanced cases. It seems doubtful that this type of strain would account for most of the lesions initially. Fractures from other mechanical causes do not often occur at the sites commonly affected in osteomalacia, as demonstrated in Cushing's disease by the fractures in the anterior ends of the lower ribs where respiratory strain on the thoracic cage is greatest. The true fractures, and even some of the pseudofractures, occurring in cases of osteomalacia may be due to other kinds of mechanical stress, but most of the lesions are at sites where muscular or postural stress is unlikely, and where arteries lie in close contact with the bones. The most likely explanation for the occurrence of these lesions here would be some type of vascular stress.

Normal bone tends to yield to continuous pressure in a very definite way as is clearly demonstrated in the skull by patterned thinning due to the pressure of convolutions of the brain and in other bones by grooving due to pressure of blood vessels. Although the exact mechanism of bone erosion at sites of pressure is not known, it is not surprising that malacic bones should respond differently to stress than normal bones. Small breaks in the cortex of bones at the site of mechanical stress due to pulsating blood vessels, rather than muscular strain as suggested by Looser, would be followed by the laying down of callus. As osteomalacia is characterized by failure of deposition of calcium in newly formed osteoid tissue, the callus would remain uncalcified in these sites and account for the radiological and pathological appearance of the pseudofractures. That there is selective resorption, or lack of deposition of calcium adjacent to the large blood vessels, seems less likely. It is to be hoped that the correlation between the locations of blood vessels and sites of pseudofractures given here will initiate attempts at pathological or operative verification, and experi- mental study of the mechanism of this phenomenon in osteomalacia and possibly other bone diseases.

The pressure of vessels upon the bones may also account for some of the similar bands of decreased density occasionally appearing in the skeletons of patients with other conditions, such as osteogenesis imperfecta, marble bones, and Paget's disease, but these lesions occur in abnormal bone, as seen by X-ray, and their mechanism and character would vary with the disease and especially with the ability to calcify the callus formed.

\section{SUMMARY}

The location of the narrow bands of diminished density which often appear symmetrically and last for months to years in the skeletons of patients with osteomalacia, is shown to correspond with the location of main blood vessels which lie on the bones. It is suggested that the mechanical stress caused by the vessels may result in small breaks in the cortex with subsequent laying down of callus which, in osteomalacia, is uncalcified. This mechanism explains the symmetrical appearance of the pseudofractures in otherwise normal appearing bone and their location at sites not usually subjected to other mechanical stresses.

\section{BIBLIOGRAPHY}

1. Camp, J. D., and McCullough, J. A. L., Pseudofractures in diseases affecting the skeletal system. Radiology, 1941, 36, 651.

2. Milkman, L. A., Pseudofractures. Am. J. Roentgenol., 1930, 24, 29.

3. Milkman, L. A., Multiple spontaneous idiopathic symmetrical fractures. Am. J. Roentgenol., 1934, 32, 622.

4. Looser, E., Uber pathologische Formen von Infraktionen und Callusbildungen bei Rachitis und Osteomalakie und anderen Knochenerkrankungen. Zentrabl. f. Chir., 1920, 47, 1470.

5. Looser, E., Uber Spätrachitis und Osteomalakie. Klinische, röntgenologische und pathologischanatomische Untersuchungen. Deutsche Ztschr. f. Chir., 1920, 152, 210.

6. Albright, F., Burnett, C. H., Parson, W. Reifenstein, E. C., Jr., and Roos, A., Osteomalacia and late rickets. Medicine, 1946, 25, 399.

7. Pompen, A. W. M., LaChapelle, E. H., Groen, J., and Mercx, K. P. M., Hongerosteopathie (-Osteo- 
malacie). Amsterdam, 1946. Wetenschappelijke Uitgeverij, van de Amsterdamsche Boek-en Courantmaatschappij N. V.

8. Parsons, L. G., The bone changes occurring in renal and coeliac infantilism and their relationship to rickets. Arch. Dis. Childhood, 1927, 2, 198.

9. Leedham-Green, J. C., and Golding, F. C., Osteoporosis melolytica. Brit. J. Surg., 1937, 25, 77.

10. Edeiken, L., and Schneeberg, N., Multiple spontaneous idiopathic symmetrical fractures. J. A. M. A., 1943, 122, 865.
11. McCune, D. J., Mason, H. H., and Clarke, H. T., Intractable hypophosphatemic rickets with renal glycosuria and acidosis (the Fanconi syndrome). Am. J. Dis. Child., 1943, 65, 81.

12. Testut, L., Traité D'Anatomie Humaine. 8th Edition, Paris, 1929, Librairie Octave Doin, Gaston Doin, Editeur.

13. Brash, J. C., and Jamieson, E. B., Editors, Cunningham's Textbook of Anatomy. Oxford University Press, New York, 1937, 7th Ed.

14. Brailsford, J. F. Unpublished case. 